\title{
PERANCANGAN SERVICE CATALOGUE MANAGEMENT DAN SERVICE LEVEL MANAGEMENT PADA LAYANAN IT PUSAIR DENGAN MENGGUNAKAN FRAMEWORK ITIL VERSI 3
}

\author{
Diana Meiriana Selvianti ${ }^{1}$, Murahartawaty ${ }^{2)}$, Wildan Herwindo ${ }^{3)}$ \\ ${ }^{1,2}$ Program Studi Sistem Informasi, Fakultas Rekayasa Industri, Universitas Telkom \\ ${ }^{3}$ Puslitbang Sumber Daya Air, Bandung \\ Jln Telekomunikasi no 1, Dayeuh Kolot, Bandung, 40257 \\ Telp: (022) 7564108, Fax: (022) 7565200 \\ E-mail: dianameiriana@gmail.com1), murahartawaty@gmail.com2), \\ herwindowildan@gmail.com3)
}

\begin{abstract}
Pusat Penelitian dan Pengembangan Sumber Daya Air (PUSAIR) is a research and development center under the Ministry of Public Works, Republic of Indonesia. PUSAIR is a government agency that involves in the research and development of water resources. Currently, PUSAIR has implemented information technology on its operational activities. In its vision, PUSAIR wants to be the leading agency in providing technology expertise services to support the availability of reliable water resources infrastructure. Therefore, to achieve this objective, PUSAIR needs good IT Governance in order to aligning its continuity of information technology with its business needs. IT Governance has been defined in the Regulation of the Minister of Communication and Informatics in 2010 namely Law No. 14/2008 on access to public information. PUSAIR applies IT Governance using framework ITIL V3 in terms of the design of service design. The design of service design is done on domain service catalogue management and service level management. The result of the design of service design on PUSAIR's IT service produces service catalogue, service portofolio, service level agreement, operational level agreement and service level requirement documents.
\end{abstract}

\section{Abstrak}

Pusat Penelitian dan Pengembangan Sumber Daya Air (PUSAIR) merupakan Puslitbang yang berada di bawah Kementrian Pekerjaan Umum, Republik Indonesia. PUSAIR merupakan instansi pemerintahan yang bergerak di bidang penelitian dan pengembangan sumber daya air. Saat ini PUSAIR telah mengimplementasikan teknologi informasi pada kegiatan operasionalnya. PUSAIR mencanangkan dalam visinya ingin menjadi lembaga terkemuka dalam menyediakan jasa keahlian teknologi untuk mendukung tersedianya infrastruktur sumber daya air yang handal. Oleh karena itu, untuk mencapai tujuan tersebut diperlukan IT Governance yang baik agar keberlangsungan teknologi informasi selaras dengan kebutuhan bisnis PUSAIR. IT Governance telah ditetapkan dalam Peraturan Menteri Komunikasi dan Informatika tahun 2010 yaitu UU N0.14 tahun 2008 tentang Keterbukaan Informasi Publik. PUSAIR menerapkan IT Governance menggunakan framework ITIL Versi 3 dalam hal perancangan service design. Perancangan service design yang dilakukan yakni pada domain service catalogue management dan service level management. Hasil perancangan service design pada layanan IT PUSAIR ini menghasilkan dokumen service catalogue, service portofolio, service level agreement, operational level agreement dan service level requirement. Berdasarkan hasil yang diperoleh dari perancangan service design ini diharapkan akan menjadi rekomendasi dan diimplementasikan untuk meningkatkan kualitas layanan IT PUSAIR dalam hal IT Service Management.

Keywords: ITIL, service design, service catalogue management, service level management, IT governance

\section{PENDAHULUAN}

"Pemanfaatan Information technology (IT) dalam sistem kerja oleh berbagai jenis perusahaan atau organisasi bertujuan untuk meningkatkan kinerja, mencapai tujuan dan sasaran, dan meningkatkan keunggulan kompetitif organisasi" (Henderi Padeli, n.d). Teknologi informasi diterapkan agar proses bisnis perusahaan dapat dilaksanakan lebih mudah, cepat, efektif dan efisien. Teknologi informasi saat ini telah menjadi bagian yang tak terpisahkan dan terintegrasi dengan tujuan bisnis organisasi.

Pusat Penelitian dan Pengembangan Sumber Daya Air (PUSAIR) merupakan Puslitbang yang berada di bawah Kementrian Pekerjaan Umum, Republik Indonesia. PUSAIR merupakan instansi pemerintahan yang bergerak di bidang penelitian dan 
Selvianti, dkk., Perancangan Service Catalague Management dan Service Level..

pengembangan sumber daya air. Saat ini PUSAIR telah mengimplementasikan teknologi informasi pada kegiatan operasionalnya. PUSAIR mencanangkan dalam visinya ingin menjadi lembaga terkemuka dalam menyediakan jasa keahlian teknologi untuk mendukung tersedianya infrasruktur sumber daya air yang handal (Laporan Assesment Sistem Networking dan Infrastruktur PUSAIR, 2013). Oleh karena itu, untuk mencapai tujuan tersebut diperlukan IT Governance yang baik agar keberlangsungan teknologi informasi selaras dengan kebutuhan bisnis PUSAIR.

Pada PUSAIR terdapat unit kerja yang bertugas menangani layanan terkait dengan IT, unit kerja tersebut dinamakan divisi IT. Divisi IT PUSAIR melayani tiga layanan utama yaitu jaringan, sistem informasi dan internet. Posisi IT di PUSAIR saat ini masih sebagai business support karena IT hanya sebagai pendukung dalam kegiatan operasional bisnisnya. Terdapat banyak kendala yang dihadapi oleh divisi IT PUSAIR yang berupa tidak berjalannya sistem dengan sebagaimana mestinya, terjadinya penurunan kinerja, ketidaksesuaian data, gangguan operasional sistem dan lain - lain. Dengan demikian harus segera ditemukan solusi untuk menangani kendala - kendala tersebut sehingga layanan IT dapat berjalan dengan baik untuk mendukung kegiatan operasional PUSAIR.

Perancangan IT Governance yang baik mampu meningkatkan efisiensi waktu pelayanan dan kepuasan user yang menggunakan layanan teknologi informasi. Pelaksanaan penyampaian layanan teknologi informasi di PUSAIR masih belum diterapkan standar jelas mengenai tanggung jawab layanan dan penanganan masalah yang terjadi. Selain itu, berdasarkan data keluhan pelanggan (user) masih banyak ditemukan keluhan yang berulang disebabkan karena kurangnya perencanaan dalam melaksanakan pelayanan teknologi informasi. Oleh karena itu, diperlukan perencanaan yang lebih matang berdasarkan best practice yang telah teruji penggunaannya.

Service design pada proses service catalogue management dan service level management memberikan panduan untuk merancang pengembangan layanan dan IT Service Management. IT Service Management diperlukan untuk meningkatkan kualitas layanan sesuai dengan tingkat (level) yang disepakati yang bertujuan untuk memberikan layanan yang bernilai dan sesuai dengan kebutuhan user. Divisi IT PUSAIR perlu menerapkan pengelolaan layanan yang disediakan agar layanan yang diberikan dapat diterima dengan efektif dan efisien oleh user.

Dalam dokumen rencana strategisnya, PUSAIR menyatakan bahwa pengembangan teknologi informasi pada dasarnya dilaksanakan untuk mendukung pelaksanaan tugas dan fungsi para pihak yang berkepentingan (stakeholder) yang menghasilkan informasi mengenai kesiapan pakai layanan teknologi informasi dan pemberian layanan keahlian untuk memecahkan persoalan - persoalan yang terjadi serta ditunjang dengan pengembangan sarana dan prasarana litbang (laboratorium) (Review Rencana Strategi Pusat Litbang Sumber Daya Air 2010 - 2014, 2014). Namun, kondisi saat ini belum adanya pengelolaan layanan teknologi informasi yang menunjang untuk memenuhi rencana strategis tersebut di PUSAIR. Oleh karena itu, dibutuhkannya perancangan service catalogue management dan service level management dalam IT Governance untuk membuat standar-standar layanan yang disampaikan oleh divisi IT PUSAIR kepada user.

Dalam pelaksanaan IT Governance dibutuhkan sebuah framework yang akan menjadi acuan dalam melaksanakan perancangan. Ada beberapa framework yang dapat digunakan untuk membuat perancangan IT Governance diantaranya: ITIL versi 3, COBIT dan ISO 38500. Menurut survey yang dilakukan oleh ISACA pada tahun 2011, ITIL versi 3 merupakan framework yang paling banyak digunakan oleh organisasi di dunia. Selain itu, ITIL versi 3 merupakan framework yang digunakan untuk mengimplementasikan IT Service Management. Oleh karena itu, PUSAIR sangat cocok menggunakan ITIL versi 3 sebagai framework untuk membuat dan merancang IT Governance.

Saat ini PUSAIR membutuhkan perancangan Service Catalogue Management (SCM) dan Service Level Management (SLM) untuk memastikan apakah layanan tersampaikan dengan baik kepada user dan memastikan sejauh mana tingkat layanan teknologi informasi yang ada di PUSAIR, dalam hal ini akan menggunakan framework ITIL versi 3 .

Tujuan dari penelitian ini yaitu: memberikan rancangan Service Catalogue Management dan Service Level Management dengan menggunakan framework ITIL versi 3 untuk layanan yang ada pada divisi IT PUSAIR.

Adapun manfaat pada penelitian ini yaitu: hasil dari penelitian ini diharapkan dapat menjadi referensi atau masukan bagi perkembangan ilmu tata kelola teknologi informasi khususnya tata kelola berbasis layanan dengan menggunakan framework ITIL versi 3, membantu PUSAIR merancang Service Catalogue Management dan Service Level Management pada layanan yang disediakan oleh divisi IT.

\section{METODOLOGI}

Dalam penelitian ini, dibutuhkan kerangka berpikir 
yang dapat menggambarkan metode dalam memecahkan masalah secara terstruktur yang dapat disebut dengan model konseptual. Gambar 1 pada Lampiran A akan menjelaskan model konseptual yang digunakan pada penelitian ini.

Masukan untuk proses Service Catalogue Management yaitu berupa rencana strategis PUSAIR dan blueprint IT untuk divisi IT PUSAIR yang akan diolah menjadi informasi bisnis dan akan menghasilkan analisis risiko bisnis. Daftar layanan IT dan hasil dari analisis risiko bisnis akan menghasilkan service catalogue dan service portofolio yang akan digunakan untuk proses selanjutnya. Dokumen service catalogue yang dihasilkan akan digunakan untuk analisis risiko pada domain service operation dan service transition.

Masukan untuk proses Service Level Management yaitu berupa customer and user feedback yang berupa dokumen keluhan dan kepuasan user yang menggunakan layanan IT pada PUSAIR. Namun yang akan digunakan hanya dokumen keluhan user karena akan menjadi parameter pengukuran keberhasilan penyampaian layanan IT. Kemudian akan diolah bersama dengan hasil analisis dari risiko bisnis, service catalogue dan service portofolio yang merupakan output dari proses sebelumnya menjadi Service Level Agreement (SLA), Operational Level Agreement (OLA) dan Service Level Requirement (SLR). Dokumen Service Level Agreement (SLA) dan Operational Level Agreement (OLA) akan menjadi panduan untuk merancang Standard Operational Procedure (SOP) incident dan problem management.

\section{HASIL DAN PEMBAHASAN}

\subsection{Hasil}

Pada penelitian ini dirancang rekomendasi berdasarkan tiga elemen kunci ITIL versi 3 yakni: process, people, dan tools. Tahapan pertama perancangan service catalogue management dan service level management pada layanan IT PUSAIR adalah perancangan kebijakan IT mengenai proses service catalogue management dan service level management. Kebijakan ini dihasilkan dari analisis gap dan rekomendasi yang diusulkan.

Setelah membuat usulan kebijakan tata kelola IT untuk PUSAIR, langkah selanjutnya yaitu membuat prosedur untuk proses service catalogue management dan service level management. Prosedur yang merupakan Gambar 2 dan Gambar 3 dapat dilihat pada Lampiran B dan C.

Kemudian berdasarkan rekomendasi akan menghasilkan usulan struktur kerja untuk tim IT yang disesuaikan dengan kebutuhan pada proses service catalogue management dan service level management. Gambar 1 menjelaskan mengenai struktur kerja pada proses service catalogue management dan service level management.

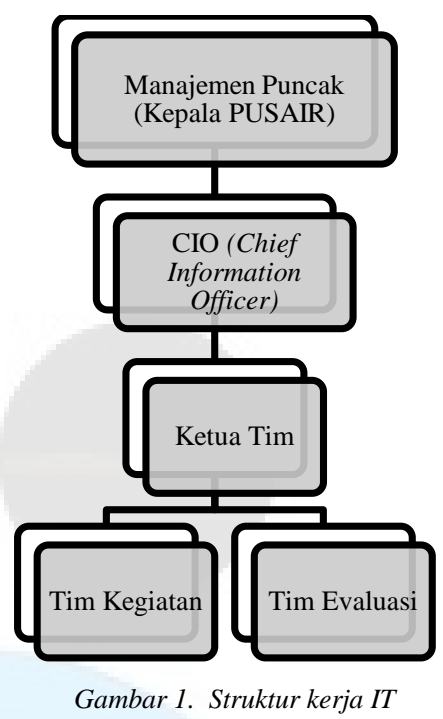

Pada proses service catalogue management, Manajemen Puncak atau Kepala PUSAIR berfungsi sebagai leadership, CIO (Chief Information Officer) sebagai service owner dan tim kegiatan sebagai project team. Pada proses service level management, CIO (Chief Information Officer) berfungsi sebagai service level manager, tim kegiatan dan tim evaluasi yang dikoordinasi oleh seorang ketua tim sebagai service level analyst.

Setelah dilakukannya perancangan struktur kerja, maka akan dirancang diagram RACI yang di dalamnya terdapat flow atau prosedur pada ITIL Versi 3 dari masing - masing proses yaitu service catalogue management dan service level management. Pemetaan diagram RACI ini dilakukan guna menjelaskan peran dan tanggung jawab antar bagian di dalam suatu proses atau aktivitas berdasarkan struktur kerja.

RACI adalah singkatan dari Responsible, Accountable, Consulted, dan Informed. RACI chart digunakan untuk menunjukkan peran dan tanggung jawab suatu fungsi di dalam perusahaan terhadap suatu aktivitas tertentu dalam IT control objective. Seperti yang kita ketahui, peran dan tanggung jawab erat hubungannya dengan proses pembuatan keputusan. Suatu keputusan di dalam perusahaan dapat dibuat oleh pihak - pihak yang memiliki kewenangan sebagai pembuat keputusan.

RACI diterapkan pada setiap aktivitas untuk mendukung kesuksesan perancangan service design dengan tujuan untuk memperjelas aktivitas, serta sebagai sarana untuk menentukan 
Selvianti, dkk., Perancangan Service Catalague Management dan Service Level..

peran dari fungsi - fungsi lainnya terhadap suatu aktivitas tertentu. RACI chart mendefinisikan apa dan kepada siapa sebuah aktivitas harus didelegasikan yang terdiri dari:

1. $\mathrm{R}$ (Responsible) artinya pihak pelaksana yang harus bertanggung jawab melaksanakan dan menyelesaikan aktivitas yang menjadi tanggung jawabnya.

2. A (Accountable) artinya pihak pelaksana yang harus mengarahkan jalannya pelaksanaan aktivitas.

3. C (Consulted) artinya pihak pelaksana yang akan menjadi tempat konsultasi selama pelaksanaan aktivitas.

4. I (Informed) artinya pihak pelaksana yang akan menjadi pihak yang diberikan informasi mengenai pelaksanaan aktivitas.

Tabel 1 dan Tabel 2 menggambarkan diagram RACI yang digunakan.

Tabel 1. Pemetaan Diagram RACI pada Proses Service Catalogue Management

\begin{tabular}{|c|c|c|c|c|}
\hline Langkah & 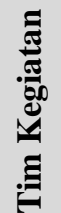 & $\stackrel{0}{0}$ & 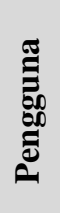 & 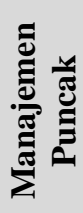 \\
\hline $\begin{array}{l}\text { Menentukan tujuan dari } \\
\text { service catalogue dan } \\
\text { service portofolio }\end{array}$ & RI & RA & $\mathrm{C}$ & $\mathrm{C}$ \\
\hline $\begin{array}{l}\text { Menentukan elemen dari } \\
\text { service catalogue dan } \\
\text { service portofolio }\end{array}$ & RI & A & $\mathrm{C}$ & $\mathrm{C}$ \\
\hline $\begin{array}{ll}\text { Menentukan model } \\
\text { pemeliharaan }\end{array}$ & RI & A & $\mathrm{C}$ & $\mathrm{C}$ \\
\hline $\begin{array}{l}\text { Mengumpulkan service } \\
\text { catalogue }\end{array}$ & RI & A & $\mathrm{C}$ & $\mathrm{C}$ \\
\hline $\begin{array}{l}\text { Mendokumentasikan } \\
\text { hubungan dan } \\
\text { dependensi layanan }\end{array}$ & RI & A & $\mathrm{C}$ & $\mathrm{C}$ \\
\hline $\begin{array}{l}\text { Membuat } \quad \text { service } \\
\text { portofolio }\end{array}$ & RI & A & $\mathrm{C}$ & $\mathrm{C}$ \\
\hline $\begin{array}{l}\text { Menyetujui dan } \\
\text { mengesahkan dokumen } \\
\text { service catalogue dan } \\
\text { service portofolio }\end{array}$ & $\mathrm{C}$ & A & I & $\mathrm{R}$ \\
\hline $\begin{array}{l}\text { Menerbitkan service } \\
\text { catalogue dan service } \\
\text { portofolio }\end{array}$ & RI & $\mathrm{R}$ & $\mathrm{C}$ & A \\
\hline $\begin{array}{ll}\text { Sosialisasi } & \text { service } \\
\text { catalogue dan } & \text { service } \\
\text { portofolio } & \end{array}$ & RI & A & $\mathrm{C}$ & $\mathrm{C}$ \\
\hline
\end{tabular}

Tabel 2. Pemetaan Diagram RACI pada Proses Service Level Management

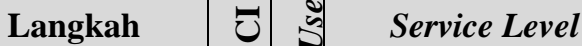

\begin{tabular}{l|c|c|c|c} 
& & & \multicolumn{2}{|c}{ Analyst } \\
\cline { 3 - 4 } & & $\begin{array}{c}\text { Tim } \\
\text { Kegiat } \\
\text { an }\end{array}$ & $\begin{array}{c}\text { Tim } \\
\text { Evaluasi }\end{array}$ \\
\hline $\begin{array}{l}\text { Menentukan } \\
\text { service level } \\
\text { requirement } \\
\text { (SLR) }\end{array}$ & $\mathrm{A}$ & $\mathrm{I}$ & $\mathrm{R}, \mathrm{I}$ & $\mathrm{C}$ \\
\hline $\begin{array}{l}\text { Membuat } \\
\text { struktur service } \\
\text { level agreement } \\
\text { (SLA) }\end{array}$ & $\mathrm{A}$ & $\mathrm{I}$ & $\mathrm{R}, \mathrm{I}$ & $\mathrm{C}$ \\
\hline $\begin{array}{l}\text { Membuat } \\
\begin{array}{l}\text { Struktur } \\
\text { operational } \\
\text { level agreement } \\
\text { (OLA) }\end{array}\end{array}$ & $\mathrm{A}$ & $\mathrm{I}$ & $\mathrm{R}, \mathrm{I}$ & $\mathrm{C}$ \\
\hline $\begin{array}{l}\text { Negosiasi SLA } \\
\text { dan OLA }\end{array}$ & $\mathrm{R}$ & $\mathrm{R}$ & $\mathrm{I}, \mathrm{C}$ & $\mathrm{C}$ \\
\hline $\begin{array}{l}\text { Mengkaji Ulang } \\
\text { SLA, OLA, dan }\end{array}$ & $\mathrm{A}$ & $\mathrm{I}$ & $\mathrm{C}, \mathrm{I}$ & $\mathrm{R}$ \\
\begin{tabular}{l} 
SLR \\
\hline $\begin{array}{l}\text { Input SLA dan } \\
\text { OLA } \\
\text { Aplikasi iTop }\end{array}$
\end{tabular} & $\mathrm{A}$ & $\mathrm{I}$ & $\mathrm{R}, \mathrm{I}$ & $\mathrm{C}$ \\
\hline $\begin{array}{l}\text { Memantau } \\
\text { kualitas layanan }\end{array}$ & $\mathrm{A}$ & $\mathrm{I}$ & $\mathrm{C}, \mathrm{I}$ & $\mathrm{R}$ \\
\hline $\begin{array}{l}\text { Melaporkan } \\
\text { layanan }\end{array}$ & $\mathrm{A}$ & $\mathrm{I}$ & $\mathrm{R}, \mathrm{I}$ & $\mathrm{C}$ \\
\hline
\end{tabular}

Selanjutnya akan digambarkan hubungan antara aplikasi tata kelola IT atau IT service management yang diusulkan yaitu iTop dengan arsitektur teknologi yang ada di PUSAIR.

Arsitektur teknologi merupakan rancangan arsitektur teknologi yang digambarkan secara terperinci sampai dengan komponen - komponen hardware, memetakan kebutuhan hardware dari sistem aplikasi, memungkinkan identifikasi hardware dan menggambarkan integrasi antar komponen sistem aplikasi yang saling berhubungan (Nurhikma, 2013). "Sasaran dari tahapan ini adalah untuk membangun arsitektur teknologi yang akan dijadikan dasar pada saat implementasi”" (Mardiansyah C. R, 2012).

Gambar 5 yang terdapat pada Lampiran D menggambarkan rancangan arsitektur teknologi usulan yang memetakan hubungan antara komponen hardware yang digunakan terhadap iTop yang merupakan aplikasi usulan yang direkomendasikan pada penelitian ini.

\subsection{Pembahasan}

Dalam penelitian ini terlebih dahulu dilakukan mapping proses service design ITIL versi 3 dengan COBIT 4.1. Pemetaan atau mapping ini dilakukan untuk dapat melakukan assessment kondisi eksisting layanan IT PUSAIR. Setelah 
didapatkan ekivalensi proses di dalam ITIL versi 3 terhadap COBIT 4.1 maka dilakukan klasifikasi berdasarkan Key Goal Indicators (KGI) dan Key Performance Indicators (KPI) dari masing - masing process goals. KGI atau yang sering disebut dengan lag indicator merupakan performance yang diharapkan untuk mencapai sebuah hasil akhir yang ingin dicapai. Sedangkan KPI atau lead indicator merupakan hasil dari kinerja yang telah dicapai.

Setelah dilakukannya pengklasifikasian berdasarkan KGI dan KPI, maka akan dilakukan pengisian terhadap bobot, target, dan realisasi. Kemudian maka akan didapatkan gap atau kesenjangan persentase keberhasilan dari tercapainya masing - masing process goals.

Selanjutnya akan dilakukan analisis risiko. Pada analisis risiko ini dilakukan analisis dampak yang mungkin terjadi ketika terjadi kesenjangan atau gap antara target dan realisasi. Kemudian dilakukan penentuan tingkat risiko yang ditentukan dari nilai bobot masing - masing KPI atau KGI namun menyesuaikan dengan penyebaran penentuan nilai bobot KPI atau KGI dari setiap process goals.

\section{SIMPULAN DAN SARAN}

Kesimpulan yang dapat diuraikan dari penelitian perancangan service design ini adalah perancangan service catalogue management dapat membantu divisi IT dalam hal mendokumentasikan segala informasi mengenai layanan IT dan mempermudah user untuk mendapatkan segala informasi terkait layanan IT yang disediakan oleh divisi IT dan perancangan service level management dapat memberikan pandangan yang sama antara user dan penyedia layanan (divisi IT) mengenai informasi tingkat layanan yang disepakati.

Adapun saran bagi Pusat Penelitian dan Pengembangan Sumber Daya Air (PUSAIR) dalam penelitian ini yakni menerapkan rekomendasi sesuai dengan perancangan service design yang dilakukan pada penelitian ini dan melakukan review dan monitoring terhadap pengimplementasian rekomendasi yang dilakukan pada penelitian ini.

Saran bagi penelitian selanjutnya yakni merancang sub domain atau proses yang belum ada pada penelitian perancangan service design ini, seperti design coordination (DC), capacity management (CM), avaibility management (AM), IT service continuity management (IT SCM), information security management (ISM), dan supplier management (SC) serta merancang tata kelola IT menggunakan framework ITIL Versi 3 untuk domain lainnya seperti service strategy dan continual service improvement.

\section{DAFTAR RUJUKAN}

Dr. Ir.F. Mulyantari, M., Yusuf, ST, A., Yuniarti, ST, T., Nuryanti, ST, G., Dewi, SE, R. N., \& Pratama, ST, B. (2014). Review Rencana Strategi Pusat Litbang Sumber Daya Air 2010 - 2014. Bandung.

INTEGRASI, PT. Adhiyasa Rekamandiri Sistem. (2013). Laporan Assesment Sistem Networking dan Infrastruktur PUSAIR. Bandung: ARSI

Mardiansyah, C. R. (2012). Analisis dan Pengembangan Enterprise Arsitektur Menggunakan Framework TOGAF Pada Pengadilan Agama Bandung. Bandung.

Nurhikma. (2013). Manajemen Teknik Informasi “IT ARCHITECTURE". Ujung Pandang.

Pedeli, H.(n.d.). Support for Good Governance.1.

\section{LAMPIRAN}

$\begin{array}{lll}\text { Lampiran A } & : & \text { Model konseptual } \\ \text { Lampiran B } & : & \begin{array}{l}\text { Prosedur service } \\ \text { catalogue management }\end{array} \\ \text { Lampiran C } & : & \begin{array}{l}\text { Prosedur service level } \\ \text { management }\end{array} \\ \text { Lampiran D } & : & \text { Arsitektur teknologi }\end{array}$




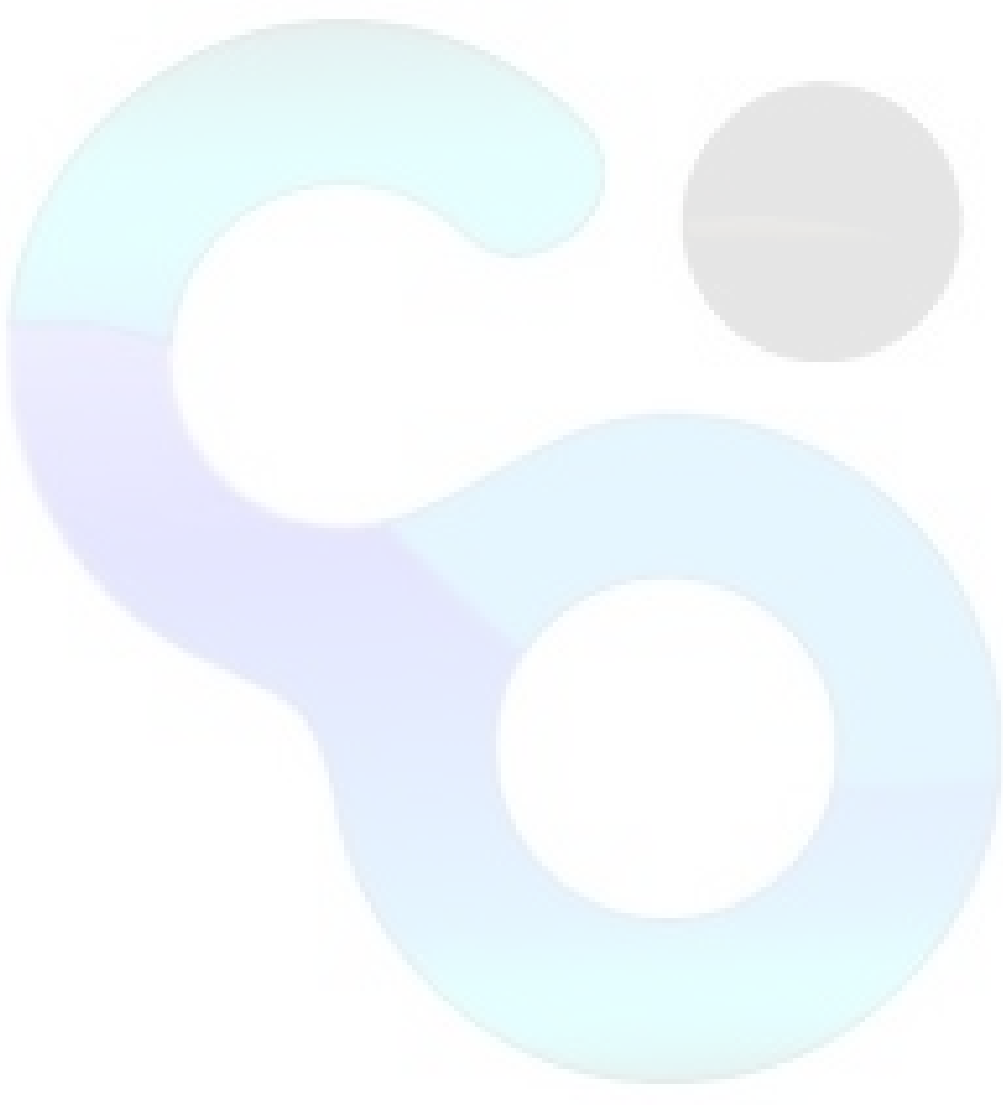




\section{LAMPIRAN A}

Model konseptual

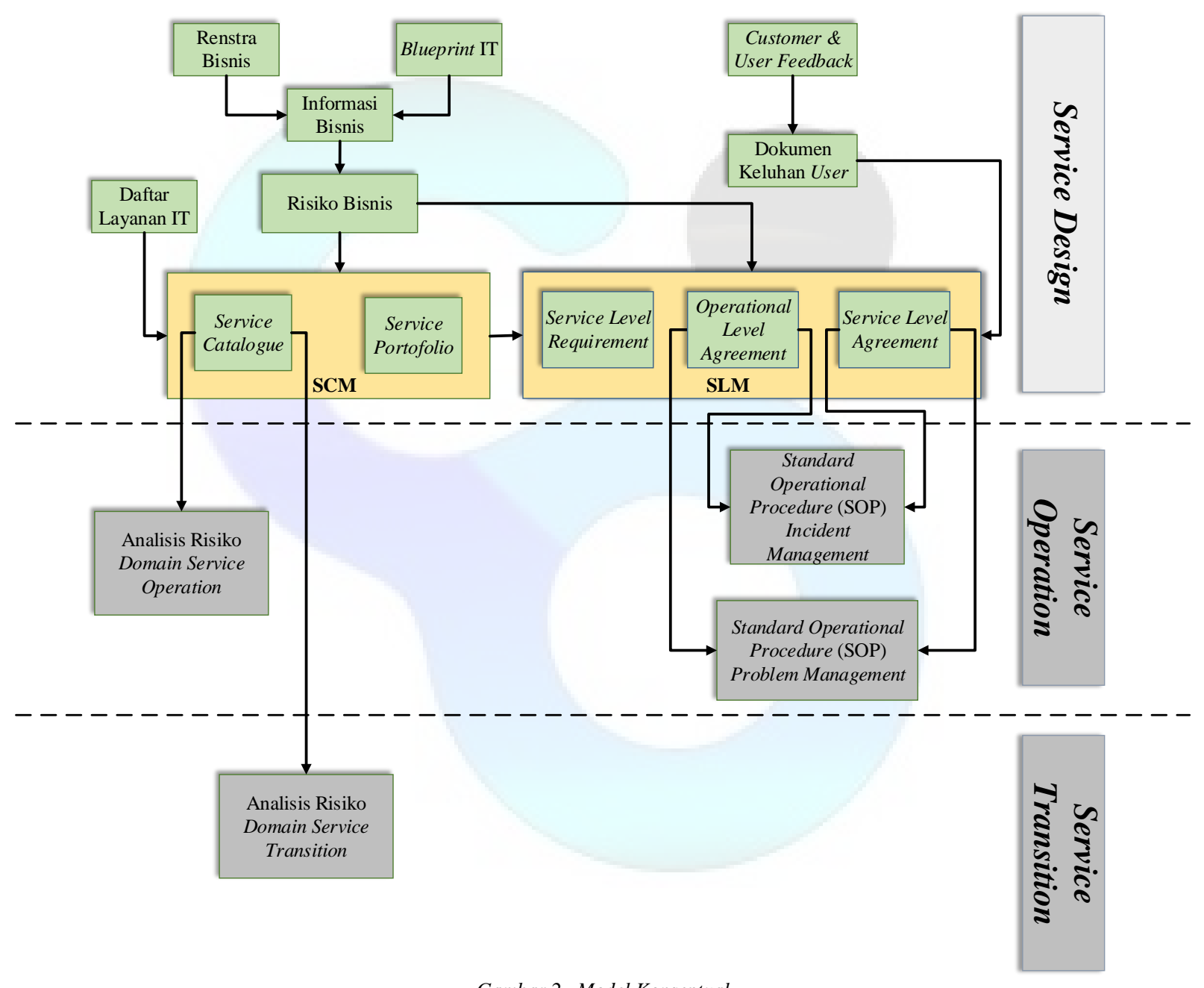

Gambar 2. Model Konseptual 


\section{LAMPIRAN B}

Prosedur Service Catalogue Management

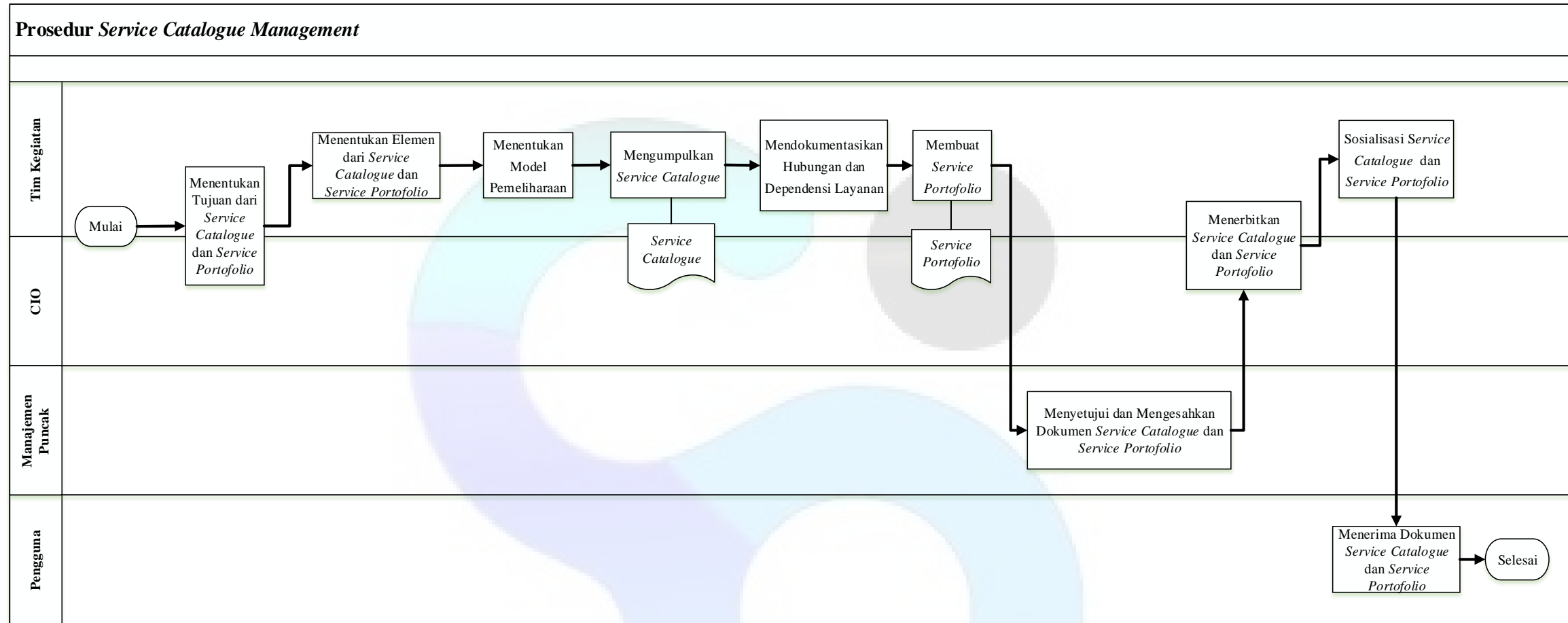

Gambar 3. Prosedur Service Catalogue Management 


\section{LAMPIRAN C}

Prosedur Service Level Management

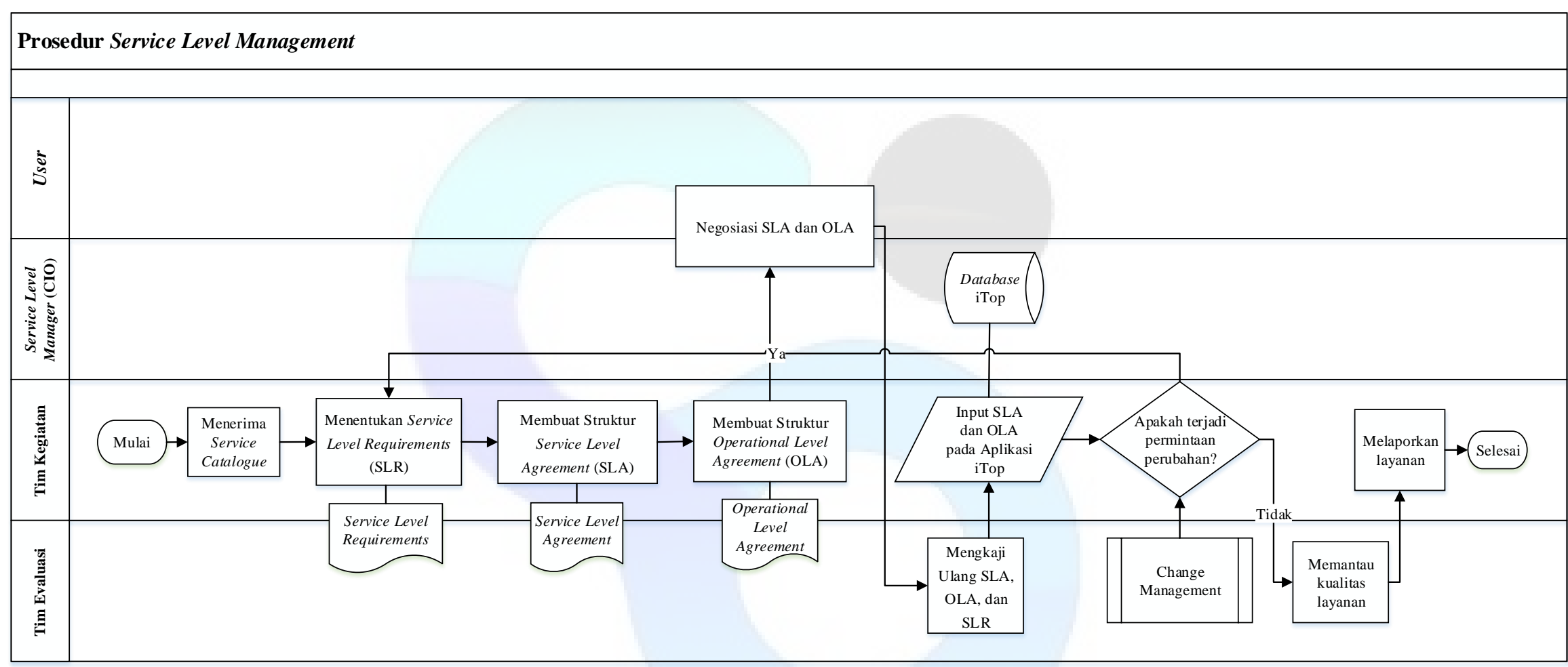

Gambar 4. Prosedur Service Level Management 
LAMPIRAN D

Arsitektur Teknologi

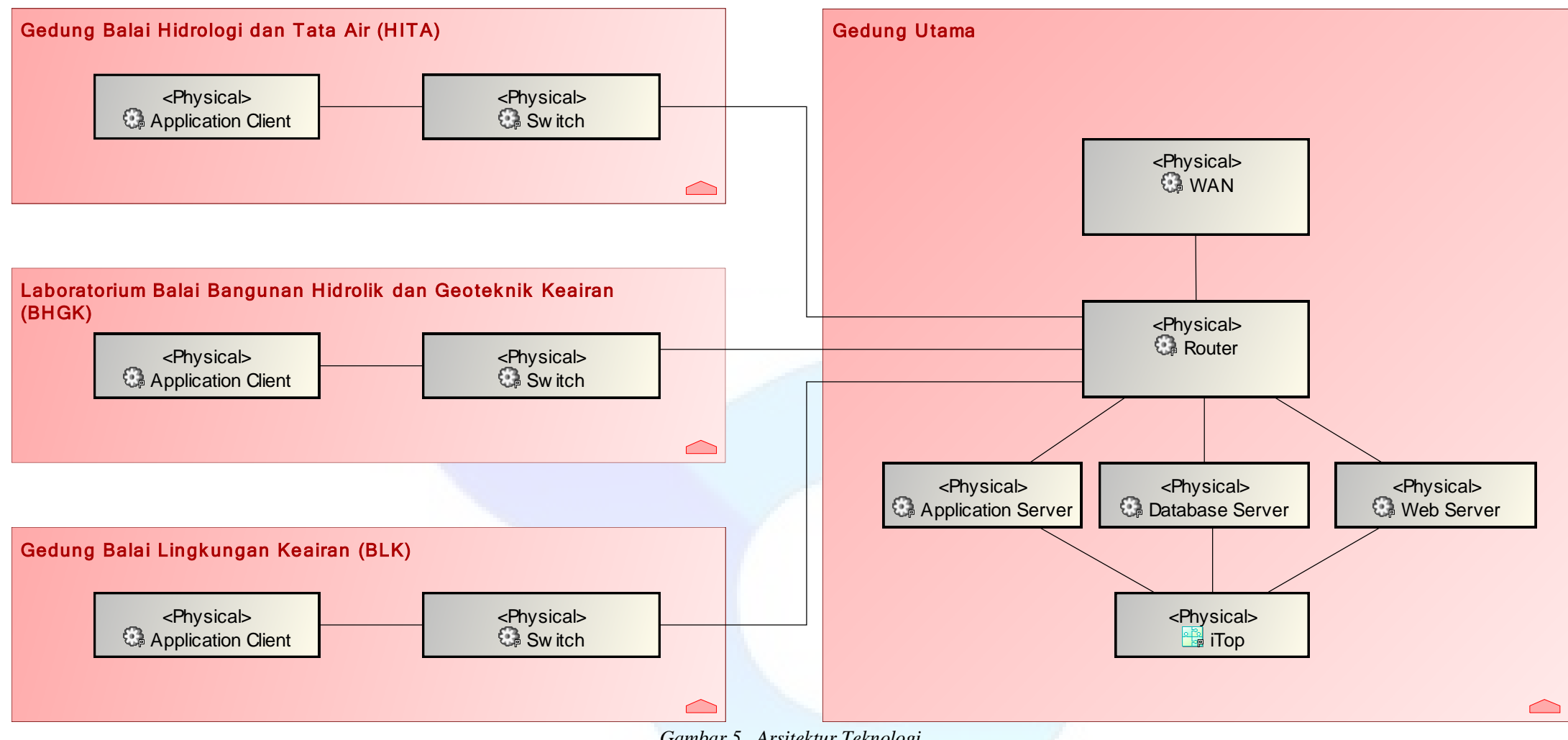

Gambar 5. Arsitektur Teknologi 